\title{
Detection of local site conditions influencing earthquake shaking and secondary effects in Southwest-Haiti using remote sensing and GIS-methods
}

\author{
B. Theilen-Willige \\ TU Berlin, Institute of Applied Geosciences, Berlin, Germany
}

Received: 22 February 2010 - Revised: 7 May 2010 - Accepted: 12 May 2010 - Published: 10 June 2010

\begin{abstract}
The potential contribution of remote sensing and GIS techniques to earthquake hazard analysis was investigated in SW-Haiti in order to improve the systematic, standardized inventory of those areas that are more susceptible to earthquake ground motions or to earthquake related secondary effects such as landslides, liquefaction, soil amplifications, compaction or even tsunami-waves. Geophysical, topographical, geological data and satellite images were collected, processed, and integrated into a spatial database using Geoinformation Systems (GIS) and image processing techniques. The GIS integrated evaluation of satellite imageries, of digital topographic data and of various open-source geodata can contribute to the acquisition of those specific tectonic, geomorphologic/topographic settings influencing local site conditions in Haiti and, thus, to a first data base stock. Using the weighted overlay techniques in GIS susceptibility maps were produced indicating areas where causal factors influencing surface-near earthquake shock occur aggregated and interfering each other and, thus, rise the susceptibility to soil amplification. This approach was used as well to create landslide and flooding susceptibility maps.
\end{abstract}

\section{Introduction}

At 4:53 p.m. LT on 12 January 2010, a 7.0-magnitude earthquake struck Hispaniola Island, just $15 \mathrm{~km}$ southwest of the Haitian capital of Port-au-Prince. Besides its strong magnitude, the earthquake's depth of about $10 \mathrm{~km}$ ensured that the densely populated capital suffered violent shaking. The major earthquake was followed by an aftershock sequence along the western end of the fault rupture, including magnitude 5.9 and 5.5 events.

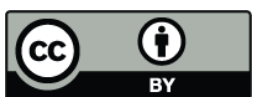

Correspondence to: $\mathrm{B}$. Theilen-Willige (barbara.theilen-willige@t-online.de)
It is obvious that many of the buildings that collapsed during the Haitian earthquake were poorly designed or constructed, often with inadequately reinforced concrete frames. When considering new planning and rebuilding of Port-auPrince, local site conditions influencing earthquake shock have to be taken into account. It can be helpful for disaster preparedness in case of further stronger earthquakes to know which areas might be prone more to earthquake shock than others due to local site conditions that play an important role when analyzing damage intensities and their local variations.

\subsection{Local site conditions}

Local geologic conditions are the cause of difference in earthquake shock intensity. But there is few certainty of the particular conditions in a specific area that are most responsible, and the degree to which they affect earthquake shaking. The ground motion during an earthquake predominantly depends on several factors such as the magnitude, properties of fault plane solutions, the distance from the fault and local geologic conditions. The most intense shaking experienced during earthquakes generally occurs near the rupturing fault area, and decreases with distance away from the fault. Within a single earthquake event, however, the shaking at one site can easily be stronger than at another site, even when their distance from the ruptured fault is the same (Gupta, 2003).

The variability in earthquake-induced damage is mainly determined by the local lithologic and hydrogeological conditions. These conditions, intern influence the amplitude, the frequency and duration of ground motion at a site. Flat areas (below $10^{\circ}$ slope gradient) within morphologic basins and depressions are usually covered by younger, unconsolidated sediments. Ground with high liquefaction response is composed of those newly formed sediments. Soft soils can amplify shear waves and, thus, amplify ground shaking. These unconsolidated sediments slow the velocity of the earthquake waves, are trapping the energy and causing large amplitudes

Published by Copernicus Publications on behalf of the European Geosciences Union. 
of shaking. The fundamental phenomenon responsible for the amplification of motion over soft sediments is the trapping of seismic waves due to the impedance contrast between sediments and underlying bedrock. When the structure is horizontally layered, this trapping affects body waves, which travel up and down in the surface layers. When lateral heterogeneities are present (such as thickness variations in sediment-filled valleys), this trapping also affects the surface waves, which develop on these heterogeneities. The interferences between these trapped waves lead to resonance patterns, the shape and the frequency of which are related with the geometrical and mechanical characteristics of the structure (Ehret and Hannich, 2004).

Groundwater level variations and associated saturation changes in sand layers within near-surface aquifers can influence local response spectra of the ground motion, through modification of shear-wave velocity. Changes of the groundwater level can also have a considerable influence on the liquefaction potential of a region. In-situ pore-water pressure responses in aquifers during earthquakes can explain the triggering mechanism of liquefaction (Hannich et al., 2006). Wetlands generally have a higher damage potential during earthquakes due to longer and higher vibrations.

Earthquake damage can be amplified by guided seismic waves along fault zones. Seismic waves travelling in the subsurface might be refracted at sharply outlined discontinuities as faults, and, thus, arrive at a summation effect that influences the damage intensity. Fault segments, their bends and intersection are more apt to concentrate stress and amplify seismic shock. Intersecting fault zones could cause constructive interference of multiple reflections of seismic waves at the boundaries between fault zones and surrounding rocks. The highest risk must be anticipated in junctions of differently oriented ruptures, especially where one intersects the other. Compact fault zones consisting of distinct segments can be considered to be more dangerous in term of seismic risk than those, where active ruptures are scattered over a larger area. Lineament analysis can contribute to the detection of surface-near faults and fracture zones and, thus, provide an assumption where summation effects can be expected (Theilen-Willige et al., 2008, 2009).

Earthquakes cause damage to buildings and other structures both in near and far fields. This phenomenon of far field damages to buildings has been reported, worldwide, notable being the 1985 Mexico earthquake, where the epicenter was $400 \mathrm{~km}$ offshore from the Mexico city, which suffered very heavy damage (Steinwachs, 1988). This observation emphasizes the importance of local site conditions in either reducing or enhancing the earthquake hazard in a region.

Maps of seismic site conditions on regional scales require substantial investment in geological and geotechnical data acquisition and interpretation. Macroseismic maps that can help to detect local site conditions in Haiti are based on different standards and scales. There is a strong need to improve the systematic, standardized inventory of areas that are more susceptible to earthquake ground motions or to earthquake related secondary effects such as landslides, liquefaction, soil amplifications, compaction or tsunami-waves. Therefore a uniform data base with a common set of strategies, standards and formats should be implemented.

Topographic variations can be considered as an indicator of near-surface lithology to the first order; with steep mountains indicating rock, nearly-flat basins indicating soil, and a transition between the end members on intermediate slopes. In the seismically active region of Haiti, information about surficial geology and shear-wave velocity $\left(V_{\mathrm{S}}\right)$ either varies in quality, varies spatially, or is not accessible. The similarity between the topography and the surficial site condition map, derived from geology is striking. Therefore, the service provided by the USGS providing Vs30 data from all over the earth's surface based on these correlations (Wald and Trevor, 2007, USGS Seismic Hazard Program, Global Vs30 Map Server) was used for these investigations in Haiti.

\subsection{Aim of this study}

Aim of this study is to investigate the potential contribution of remote sensing and GIS techniques for the detection of areas more susceptible to earthquake shock than the environment due to local site conditions in Haiti. The evaluation of satellite imageries and of digital topographic data is of great importance as it contributes to the acquisition of the specific geomorphologic/topographic settings of earthquake hazard affected areas by extracting geomorphometric parameters based on Digital Elevation Model (DEM) data. As digital elevation data such as SRTM (Shuttle Radar Topography Mission, $90 \mathrm{~m}$ spatial resolution) and ASTER-data (30 m resolution, interpolated up to $15 \mathrm{~m}$ ) are free available these data and the hereby presented, standardized approach can be used worldwide.

\section{Geologic and seismotectonic setting}

The island of Hispaniola lies along the eastern North American-Caribbean plate boundary, within the transition zone between different tectonic regimes, with subduction dominant to the east and a transform zone dominant to the west (Mann et al., 1998). Two tectonic plates meet at strikeslip faults, with the Caribbean plate moving eastward with respect to the North America plate. This boundary experiences $\sim 20 \mathrm{~mm} / \mathrm{yr}$ of plate motion through a combination of strike slip and interplate thrust faulting (Calais et al., 2002). Currently active major plate-boundary structures affecting Hispaniola include left-lateral strike-slip faults (Septentrional fault and Enriquillo-Plantain Garden fault) and an offshore fold and thrust belt (North Hispaniola Deformed Belt), that is part of the subduction zone extending beneath northeastern Dominican Republic (Dolan and Wald, 1998; Tuttle et al., 2003). The Southwestern peninsula of Hispaniola is 


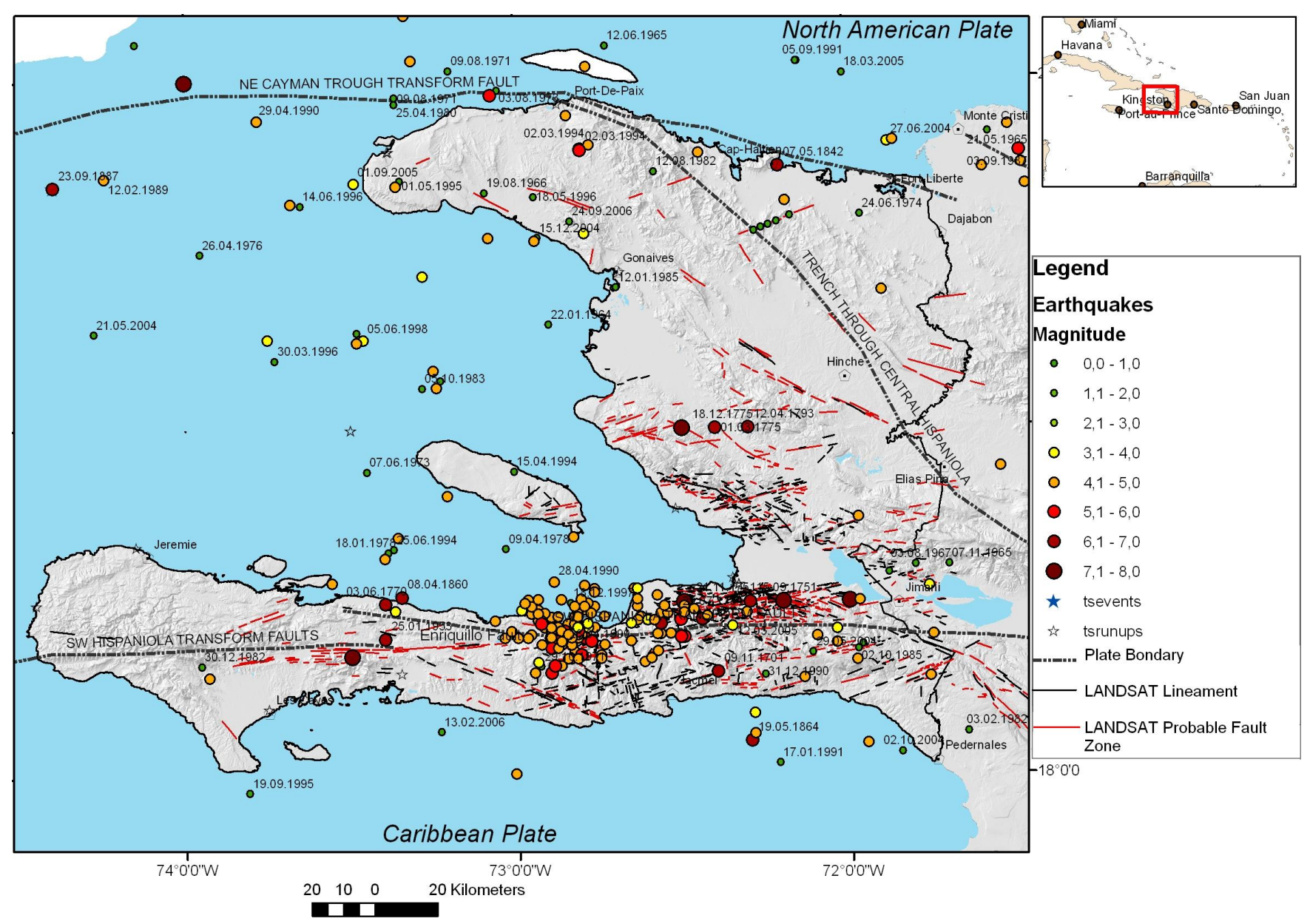

Fig. 1. Earthquakes in SW-Haiti (earthquake data: USGS, ISC, NOAA, GFZ).

considered to be a fragment of the Caribbean oceanic crust, and especially of the "Late Cretaceous Caribbean plateau basalts" (Mann et al., 1998).

Earthquakes have mainly occurred along the boundary between the Caribbean and North America plates. The 12 January earthquake was the worst to strike the region in decades, and possibly well over a century (NASA, 2010). The Haiti earthquake epicenter of 12 January 2010 is situated within the Enriquillo-Plantain Garden Fault zone (Fig. 1). Between the major fault zones there are series of interconnected fault lines. Strike-slip faults are clearly visible on satellite imageries as lineaments.

Figures 2 and 3 provide an overview of the geomorphologic setting in SW-Haiti showing mountainous areas subdivided by elongated valleys, broader basins and coastal lowlands covered by unconsolidated, Quaternary sediments. The height level map based on ASTER DEM data clearly visualizes the position of lowlands and valleys (Fig. 3). Those larger valleys and coastal areas were more affected by earthquake shock than the environment during the January 2010-earhquakes (see damage maps provided by DLR, ZKI, 2010 and Google Earth provided imageries).

\section{Methods}

GIS integrated geodata analysis can be used to detect, map and visualize factors that are known to be related to the occurrence of higher earthquake shock and/or earthquake induced secondary effects: factors such as lithology (loose sedimentary covers), basin and valley topography, fault zones or steeper slopes (Fig. 4). Morphometric maps such as slope, hillshade, height level, and curvature maps are generated based on SRTM and ASTER Digital Elevation Model (DEM) data using ArcGIS from ESRI and ENVI digital image processing software (CREASO). Step by step factors can be extracted from these data that might be of importance for the detection of local site conditions. For example: the distribution of unconsolidated, youngest sedimentary covers can often be correlated with areas showing les than $10^{\circ}$ slope gradient and no curvature. (In the case of the curvature: negative curvatures represent concave, zero curvature represent flat and positive curvatures represents convex landscapes.) Height level maps help to search for topographic depressions covered of almost recently formed sediments, which are usually linked with higher groundwater tables. When extracting the lowest height levels of an area, it becomes 


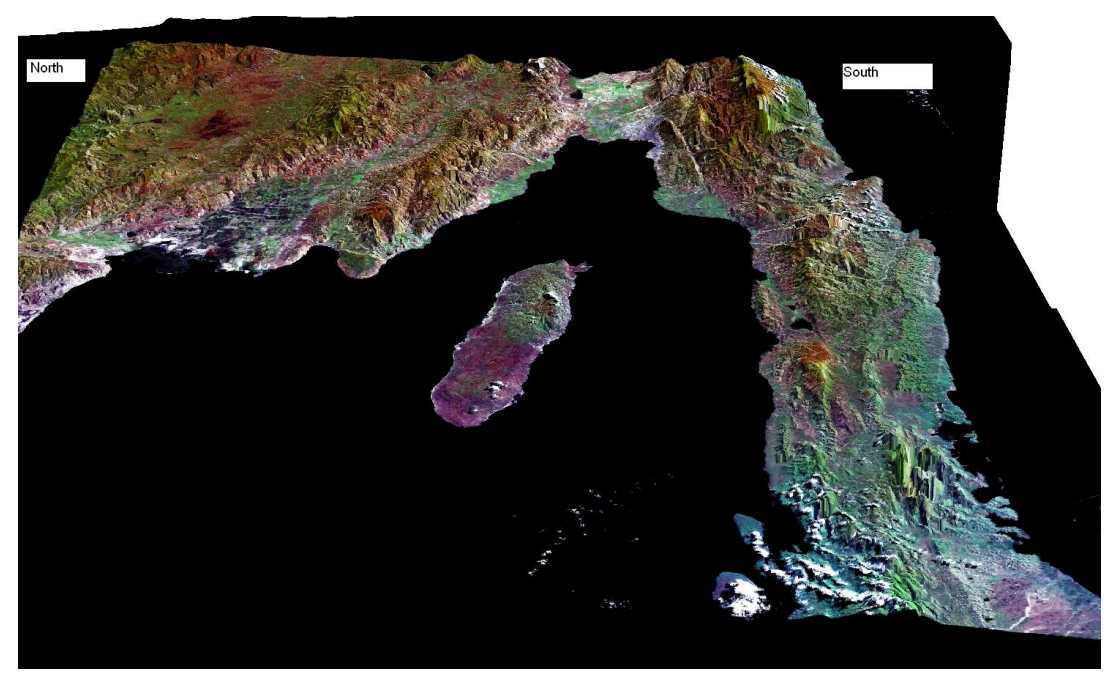

Fig. 2. Perspective 3-D-view of a LANDSAT ETM image of Haiti merged with ASTER DEM data looking to east.

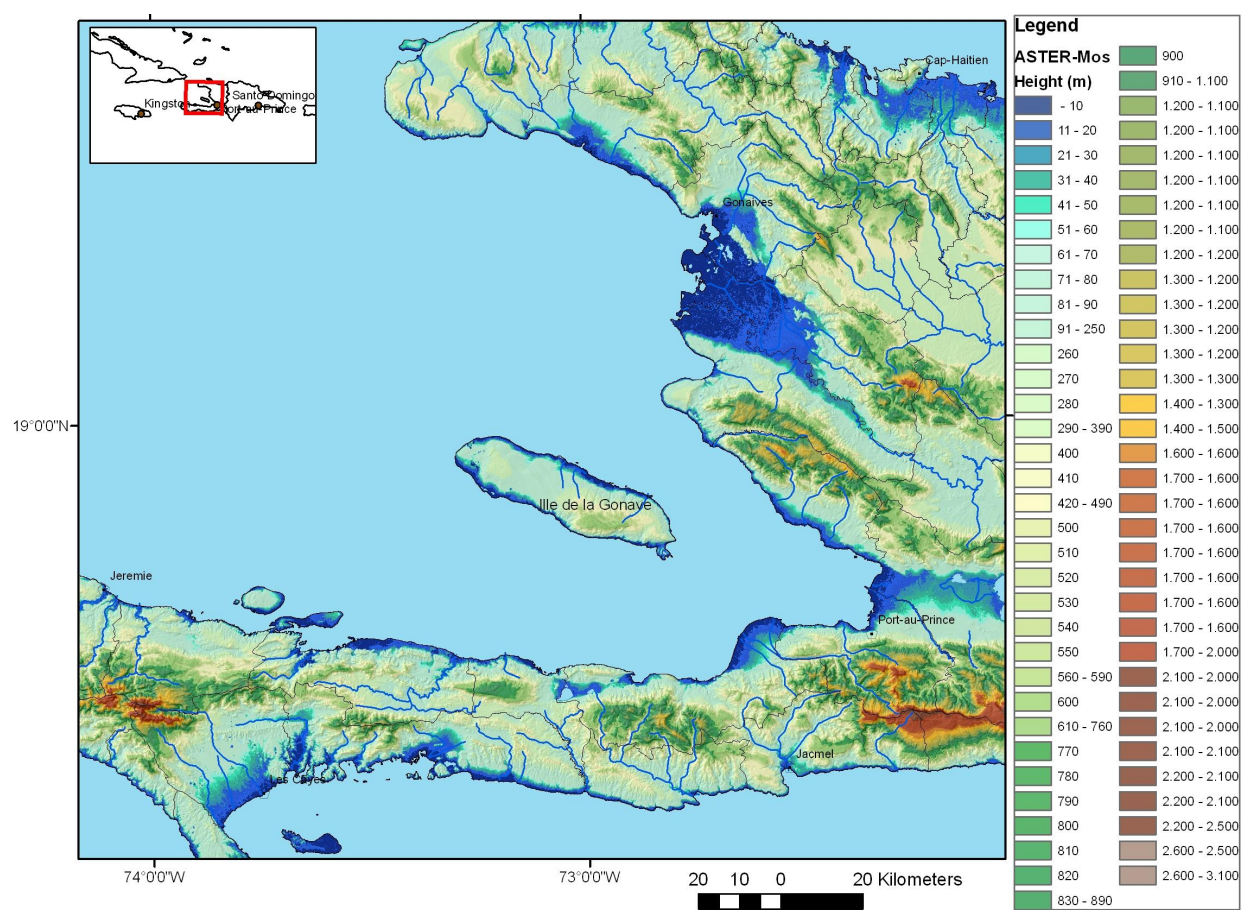

Fig. 3. Height level map based on ASTER GDEM data visualizing lowlands (dark-blue).

visible where the areas with high ground-water tables can be expected (Fig. 4). In case of earthquakes those areas have often shown the highest earthquake damage intensities (Schneider, 2004).

Slope gradient maps help to detect those areas where mass movement are likely to occur. From slope gradient maps are extracted those areas with the steepest slopes, and from curvature maps the areas with the highest curvature as these are susceptible to landslides. Slopes with higher slope gradient $\left(>20^{\circ}\right)$ are generally more susceptible to mass movements. Special attention is focussed on precise mapping of traces of faults (lineament analysis) on satellite imageries, predominantly on areas with distinct expressed lineaments, as well as on areas with intersecting/overlapping lineaments. Lineament analysis based on satellite imageries or DEM derived morphometric maps can help to delineate local surfacenear fracture systems and faults that might influence seismic wave propagation and influence the intensity of seismic shock or might influence the susceptibility to secondary effects. Areas with intersecting, larger lineaments are probably exposed to relatively higher earthquake shock in case of stronger earthquakes. 


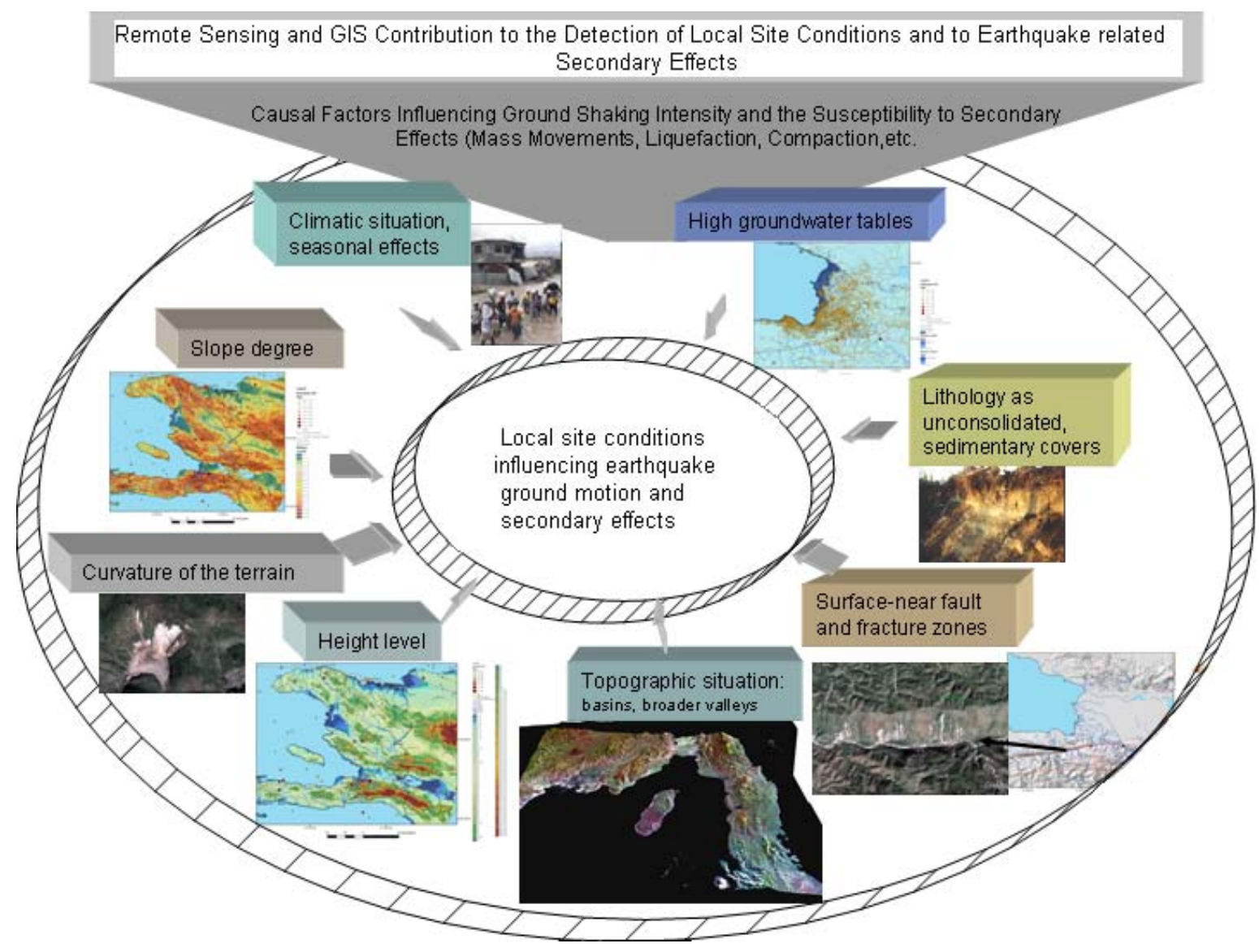

Fig. 4. Some of the causal or preparatory factors influencing earthquake ground motion and earthquake related secondary effects that can be visualized in a Geoinformation System.

Causal or preparatory factors are extracted systematically in ESRI Grid-format as indicated in Figs. 5 and 6. By combining some of the causal or preparatory factors influencing earthquake shock intensity in a georeferenced GIS environment those areas can be detected where causal factors occur aggregated and superimpose each other. From SRTM and ASTER DEM data derived causal factors such as

- lowest height levels providing information of areas with relatively higher groundwater tables (here: $0-15 \mathrm{~m}$ ),

- lowest slope gradients $\left(<10^{\circ}\right)$,

- lowest minimum curvature or no curvature, providing information of broader valleys, basins and depressions with younger sedimentary covers and higher groundwater tables,

- highest flow-accumulations, providing information of areas with higher surface water-flow input,

are combined with lithologic and seisomotectonic information in a GIS data base as
- from geologic maps derived Quaternary sediment distributions and faults,

- from LANDSAT ETM imageries derived lineaments,

- from International Earthquake Centres downloaded earthquake data (International Seismological Centre, ISC, USGS, GFZ, etc.).

Of course, many further factors and data play an important role, that - if available - should be included into the data base. The different factors are converted into ESRI-GRIDformat and summarized/aggregated and weighted in $\%$ in the weighted overlay-tool of ArcGIS (Figs. 5 and 6) according their estimated influence on the local specific conditions or in equal percentages. The percentage of influence of one factor is changing, for example due to seasonal and climatic reasons, or distance to the earthquake source. As a stronger earthquake during a wet season will probably cause more secondary effects such as landslides or liquefaction than during a dry season, the percentage of its influence has to be adapted. Therefore the percentage of the weight of the different factors has to be adjusted as well to seasonal effects. 


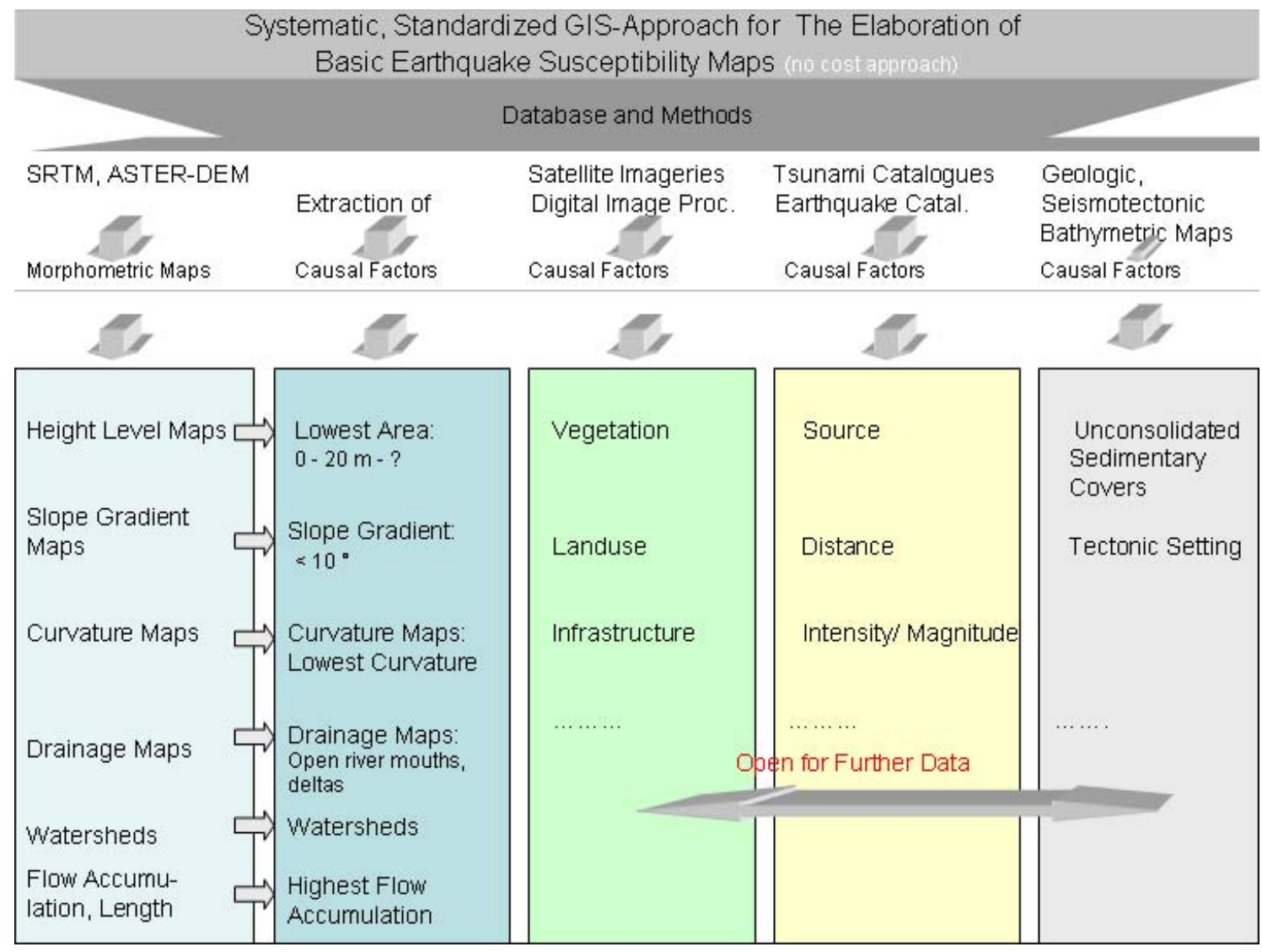

Fig. 5. Basic GIS approach for the extraction of causal factors influencing earthquake shock.

The sum over all factors/layers that can be included into GIS provides some information of the susceptibility to amplify seismic signals. After weightening (in \%) the factors according to their probable influence on ground shaking susceptibility maps of SW-Haiti can be elaborated, where those areas are considered as being more susceptible to higher earthquake shock intensities, where "negative" factors occur aggregated and interfering with each other. Whenever an earthquake happens in these areas, now it can be derived better where the "islands" of higher ground shaking are most likely to occur by adding the specific information of the earthquake to the susceptibility map using the weighted overlay - approach.

The hereby presented approach is proposed to serve as a first basic data stock for getting a perception of potential sites susceptible to higher earthquake ground motion, including in next steps the integration of further, available data such as movements along active faults, focal planes, uplift/subsidence, 3-D structure, lithologic properties and thickness of lithologic units, shear wave velocities, etc.

The analysis method and integration rules can easily be modified in the open GIS architecture as soon as additional information becomes available. The gained data base and maps can facilitate and support the planning of additional geotechnical investigations. The more geotechnical site data exist, the better and detailed the resulting susceptibility maps will be. This knowledge is essential for the planning of the rebuilt of earthquake prone areas in Haiti. The gained spatial data could be converted into Google Earth-kml-format and, thus, be available for the public in Google Earth without costs.

\section{Remote sensing and GIS contribution to the detection of local site conditions influencing earthquake ground motion and earthquake related secondary effects}

\subsection{Detection of local site conditions}

Those areas are considered to be susceptible more to soil amplification where the following causal factors are summarizing and aggregating their effects: lowest height level of the terrain combined with relative high groundwater tables, flat morphology with low slope gradients and no curvature, loose sedimentary covers within a basin topography or within flat coastal areas. When an area is underlaid by larger, active fault zones, especially when intersecting each other, the soil amplification susceptibility will probably rise as for example in the southern part of Port-au-Prince, depending on given specific earthquake properties and parameters. After 


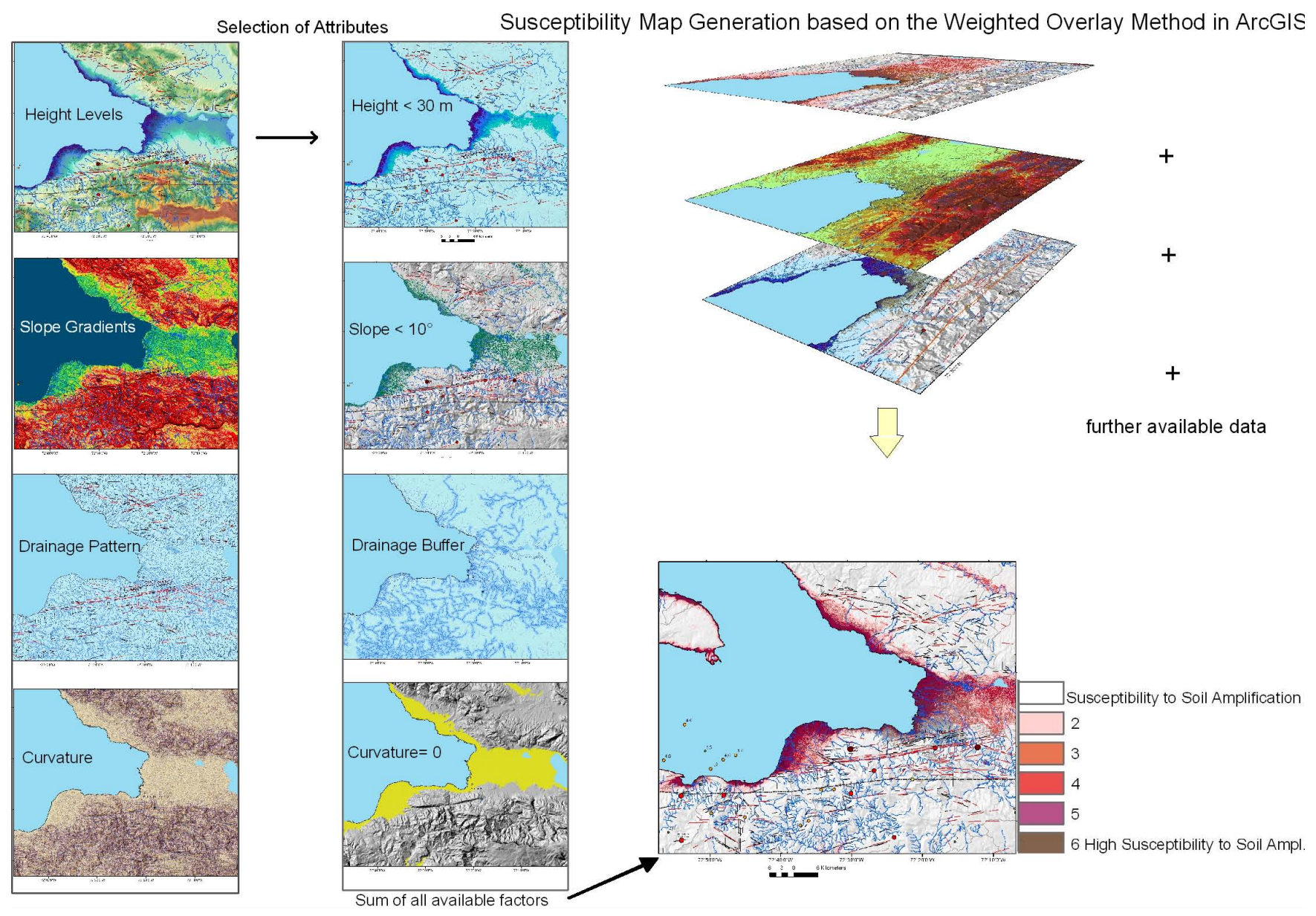

Fig. 6. Extraction and aggregation of causal factors.

extracting, aggregating and weightening the potential causal factors influencing local site conditions with different percentages of influence the following map can be presented from the area of Port-au-Prince (Fig. 7).

\subsection{Slope failure}

Numerous newly formed landslides were observed after the 12 January earthquake. The mountainous areas surrounding Port-au-Prince were subjected to landslides after the quake shattered exposed areas, especially those that were prone to previous slope failure in the past (Fig. 8). Settlements near Port-au-Prince have been built up on areas where the probability of occurrence of landslide is very high. Areas susceptible to slope failure that could be affected by stronger earthquakes should be considered when planning the rebuilt of Port-au-Prince and other cities of Haiti as the risk of further slope failure is increasing due to the subsequent loss of vegetation combined with intense rainfall events in Haiti's tropical environment.
Identification and mapping of instability factors having a relationship with the slope failures require knowledge of the main causes of landslides. These instability factors include lithologic properties of the surface rocks and soil properties, the tectonic pattern, seismicity, slope steepness and curvature, stream evolution, groundwater conditions, climate conditions, vegetation cover and landuse.

Causal or preparatory factors such as steep slopes, convex curvatures, height levels, drainage pattern and lineaments were extracted from recent LANDSAT ETM-, Google Earthand ASTER-satellite data. Landslide locations were identified in the study area from interpretation of satellite imageries. A clear relationship between the occurrence of landslides and active fault zones, height levels above $500 \mathrm{~m}$ and steep slopes is evident. The active fault segments with leftlateral movements (Enriquillo-fault) and slip-rates of about some $\mathrm{mm}$ up to $\mathrm{cm}$ per year seem to be the most determining factor influencing the distribution and occurrence of landslides. Figure 9 shows the result of the WeightedOverlay-aggregation of these main preparatory factors and lineament analysis. 


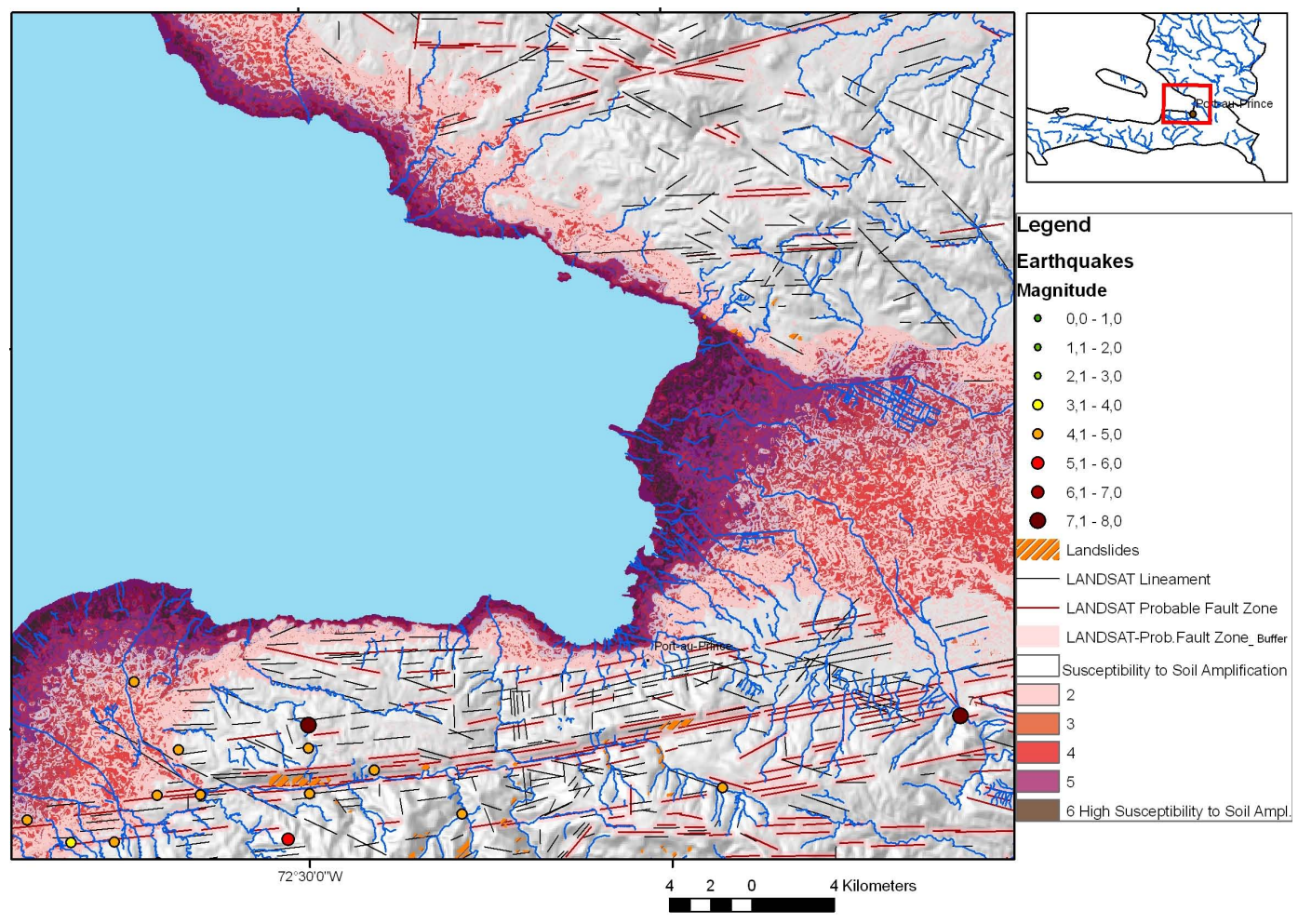

Fig. 7. Susceptibility to soil amplification according to the weighted-overlay-method based on ASTER DEM, LANDSAT data, geologic maps and earthquake data. Aggregating following factors: [height level $<10 \mathrm{~m}]+\left[\right.$ slope degree $\left.<10^{\circ}\right]+[$ curvature $=0]+[$ flow accumulation $>1]$ + [outcrop of Quaternary sediments-Grid] + [fault zones-Grid $]+\ldots$

Dark-red areas correspond to the areas where nearly all "negative" factors overlap.

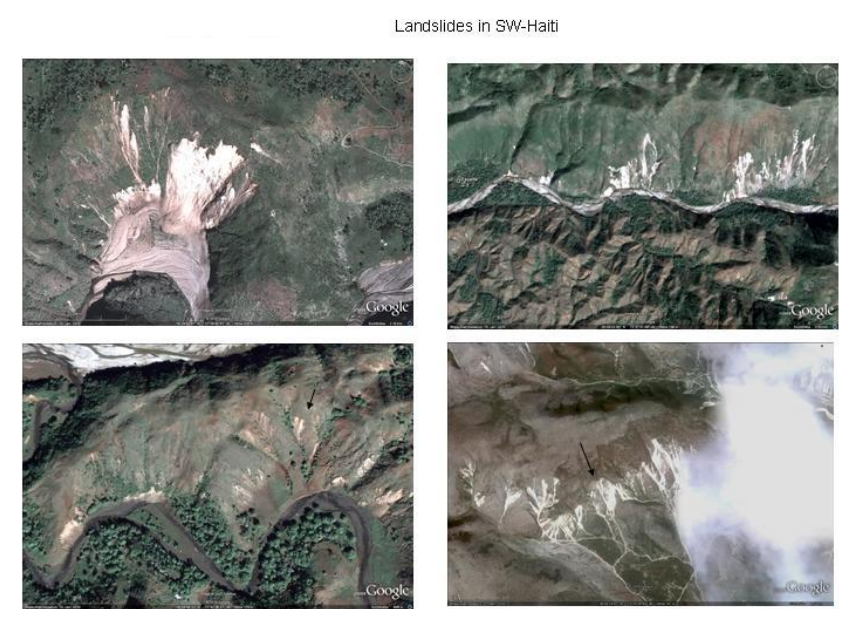

Fig. 8. Landslides as visible on Google Earth imageries in the southwest of Port-au-Prince.

This approach of landslide susceptibility mapping is valid for a generalized assessment purpose, however, is less useful on the site-specific scale, where local geological and geomorphologic heterogeneities prevail. Nevertheless this approach contributes to a better overview and understanding of the relationships between the different causal factors and helps to prepare more detailed investigations in the field.

\subsection{Flood waves}

Flooding due to storm surge, flash floods and tsunami waves is a well known phenomenon in Haiti. For example: in 2008 several hurricanes hit Haiti, leaving behind a path of destruction. More than 500 people died. Strong rain intensity as a consequence of the hurricanes led to large inundations (DLR, ZKI, 2008). Tsunami waves have been documented after the January 2010 earthquake (Lovett, 2010). An overview of tsunami events in the region is provided by NOAA's Satellite and Information Service (NESDIS).

Summarizing factors influencing flooding susceptibility such as relatively lowest height levels $(<10 \mathrm{~m})$, minimum terrain curvature (values $=0$ ), slope gradients below $10^{\circ}$ and high flow accumulation values using the weighted-overlay tools in ArcGIS helps to map areas susceptible to flooding, see Fig. 10. As river mouths form an entrance for flooding waves those areas along the river sides are even more susceptible to flooding, visualized by a $100 \mathrm{~m}$-buffer along the waterways. 


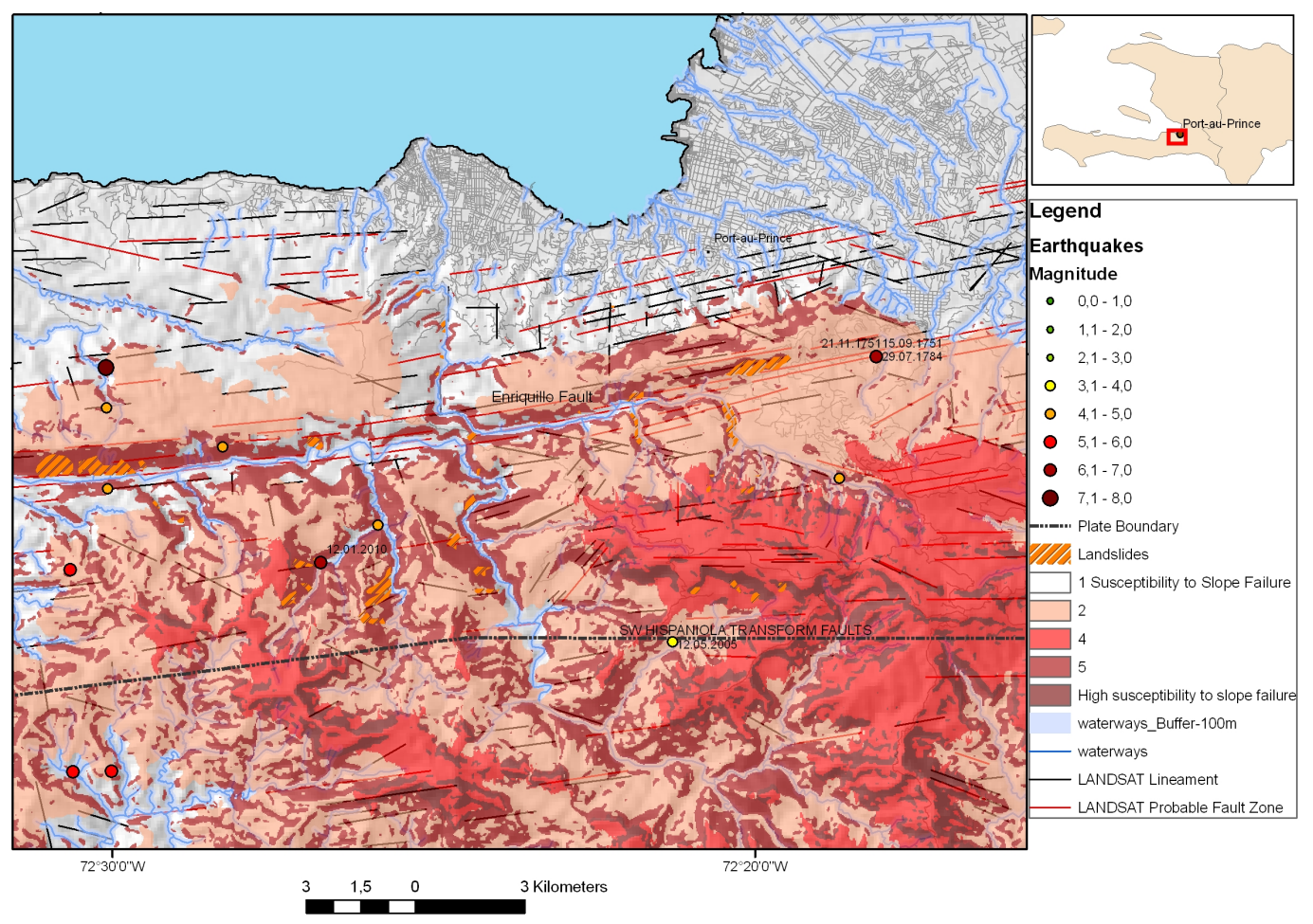

Fig. 9. Weighted overlay calculation of some of the causal factors influencing slope stability based on ASTER DEM and LANDSAT data (weighted overlay of: [slope degree $>40^{\circ}$ ] + [Maximum Curvature $>250$ ( - created in ENVI-Software in .tif-format with gray scale units between 0-255, converted into ESRI-Grid-format and classified, selection of values $>250$ )] + [height level >500 m] + [fault zones-Grid]).

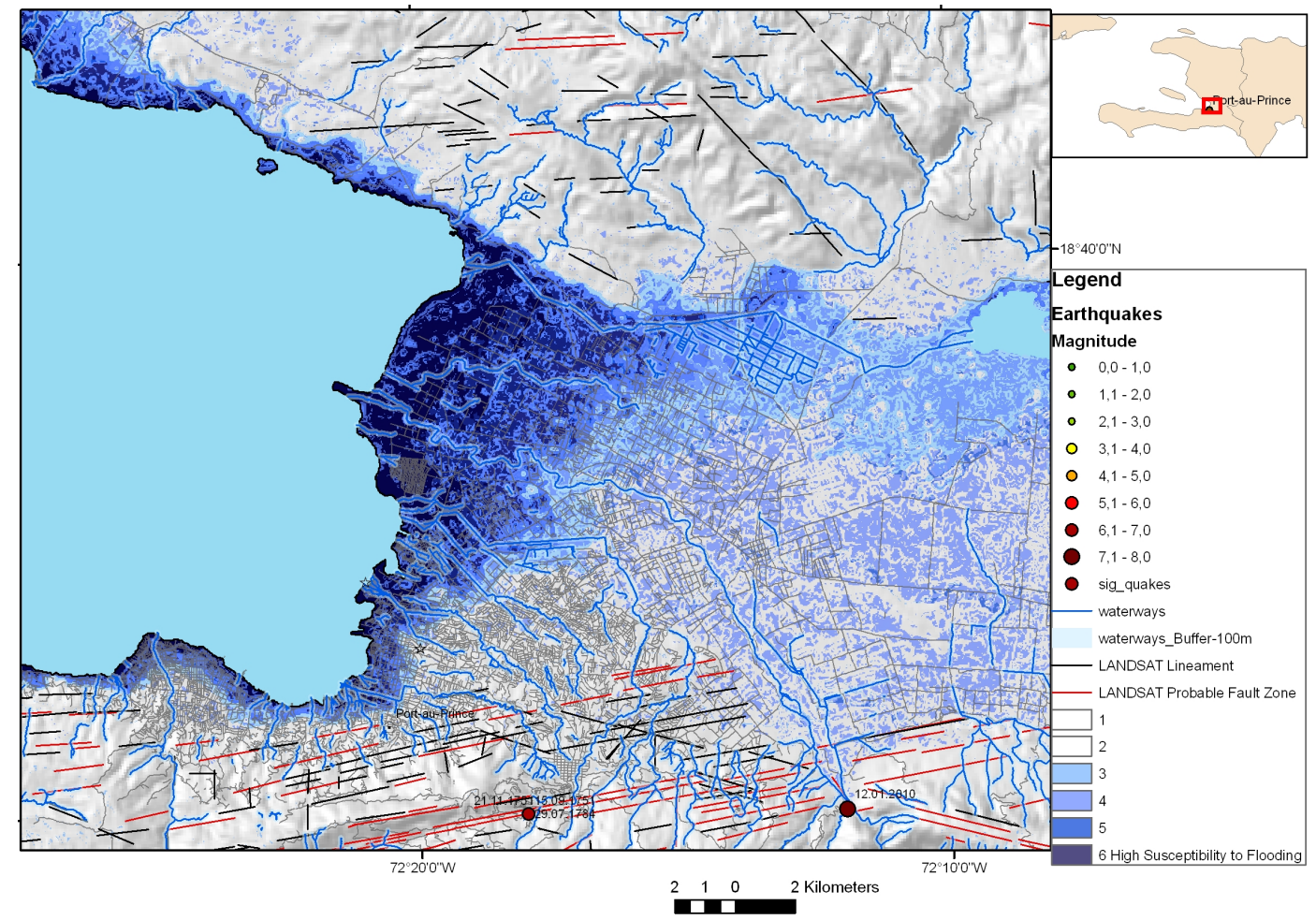

Fig. 10. Flooding susceptibility map of Port-au-Prince in case of storm surges, flash floods or tsunami waves based on the aggregation of the following factors in the weighted overlay-tool of ArcGIS: [height level $<5-10 \mathrm{~m}$ ] + [slope degree $\left.<10^{\circ}\right]+[$ curvature $=0$ ] $+[$ high flow accumulation]+ river mouths and estuaries-Grids. 


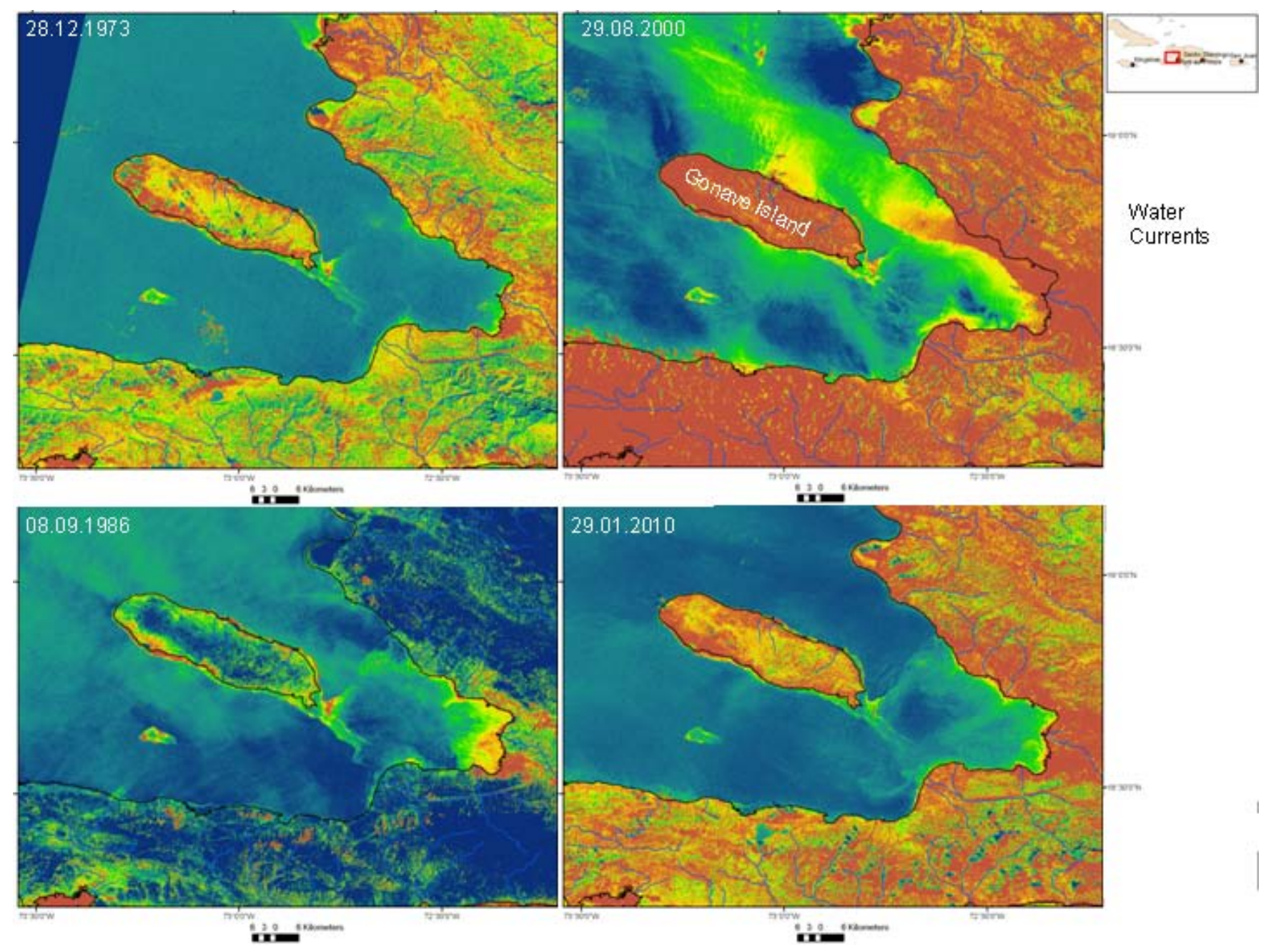

Fig. 11. Surface-near water streaming pattern as visible on colour-coded LANDSAT Multispectral Scanner (MSS) and Thematic Mapper (TM) - imageries, RGB-Bands 2, 4, and 5.

In case of storm floods or stronger tsunami events the coastal morphology and islands will influence flooding dynamics. The evaluation of LANDSAT imageries can contribute to a better understanding of surface-near water streaming mechanisms. When colour-coding and classifying LANDSAT imageries of different acquisition dates water currents become visible (Fig. 11). The unsupervised classification of the LANDSAT 29 August 2000-RGB-image enhances the visibility of the streaming pattern (Fig. 12). Due to the position of the elongated Gonave island in front of Port-au-Prince streaming seems to be focussed towards the northern part of the bay as visible on the classified LANDSAT scene (Fig. 12). In case of tsunami waves it can be assumed that the coastal morphology will cause similar effects and therefore the northern part of the bay probably will be more affected. Evaluations of LANDSAT imageries clearly show traces of former flooding events in the northern part of the bay (Fig. 13).

\section{Shear wave velocities}

Shear-wave velocity is an important factor when investigating local soil conditions. A standardized approach for mapping seismic site conditions measuring or mapping shearwave velocity $\left(V_{\mathrm{S}}\right)$ was developed by Wald and Allen (2007). As in many seismically active regions of the world, information about surficial geology and $V_{\mathrm{S}}$ either, does not exist, varies dramatically in quality, varies spatially, or is not easily accessible Wald and Allen first correlated Vs30 (here Vs30 refers to the average shear-velocity down to $30 \mathrm{~m}$ ) with topographic slope $(\mathrm{m} / \mathrm{m})$ at each Vs30 measurement point for data. The basic premise of the method is that the topographic slope can be used as a reliable proxy for Vs30 in the absence of geologically and geotechnically based site-condition maps through correlations between Vs30 measurements and topographic gradient. By taking the gradient of the topography and choosing ranges of slope that maximize the correlation 


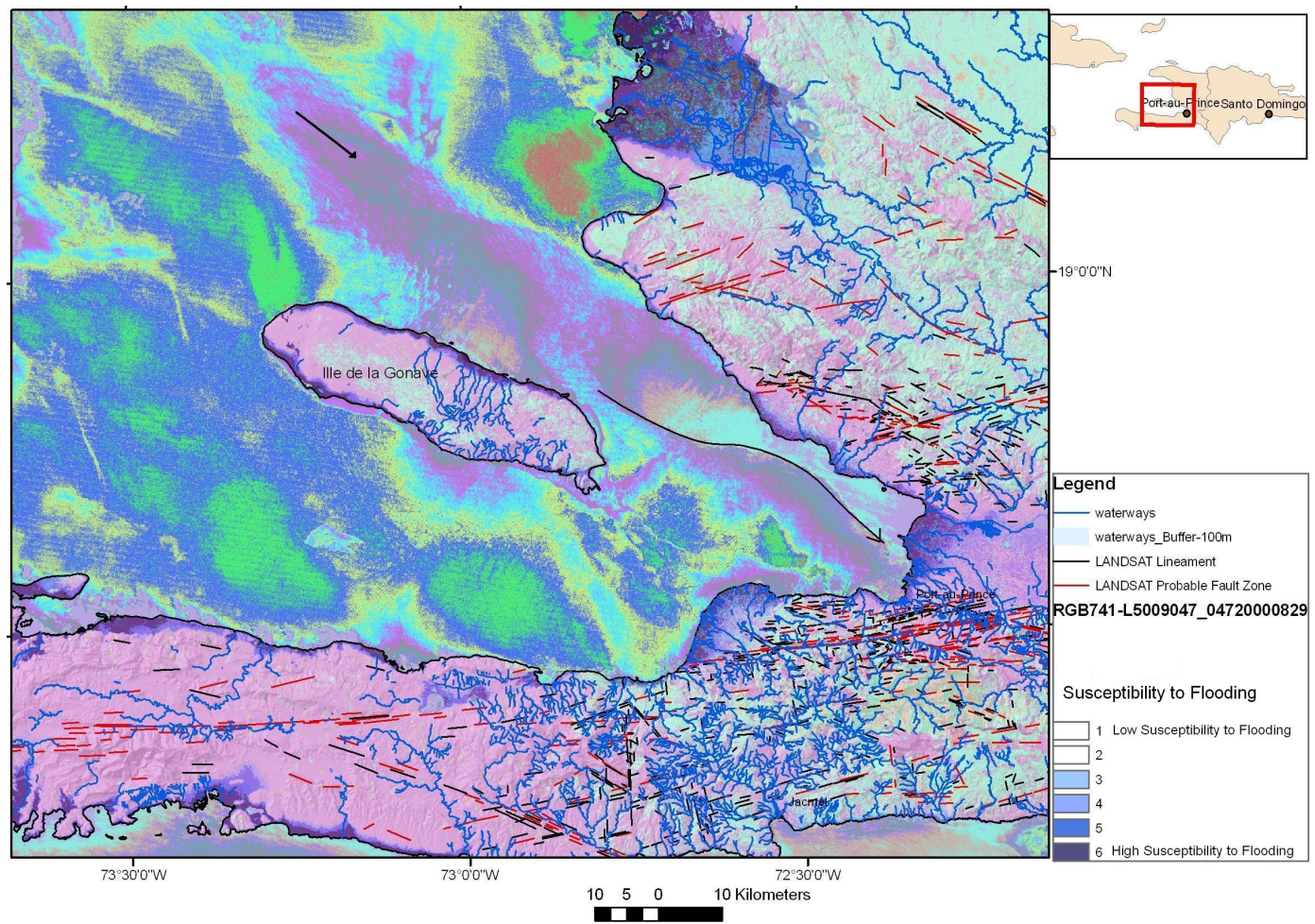

Fig. 12. Unsupervised classification of the LANDSAT TM image (acquisition date: 28 August 2000) showing surface-near streaming patterns.

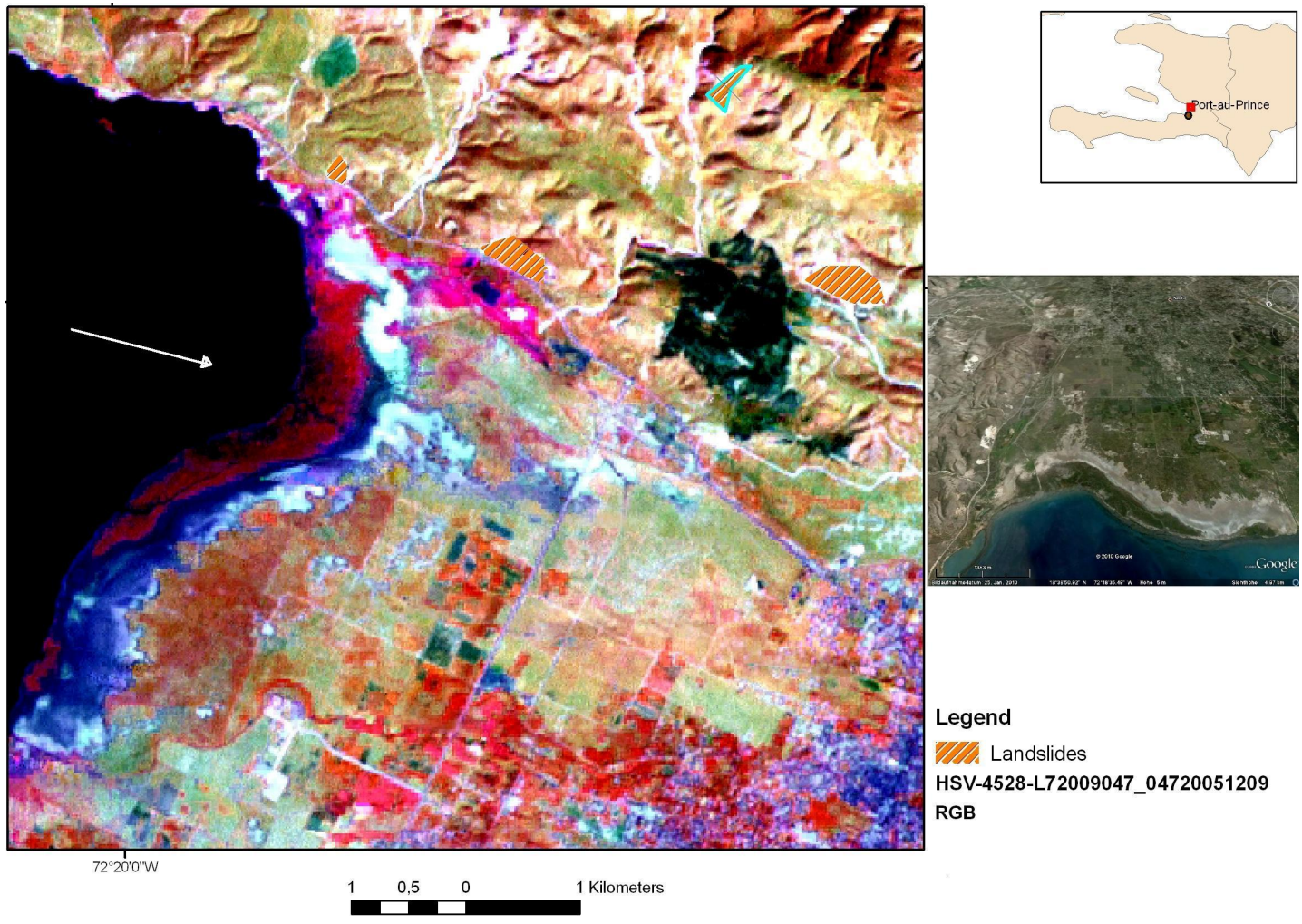

Fig. 13. Traces of former flooding events visible on the LANDSAT Enhanced Thematic Mapper (ETM) scene of 9 December 2005, RGB, Bands 4, 5, 2, 8 and on Google Earth provided imageries. 


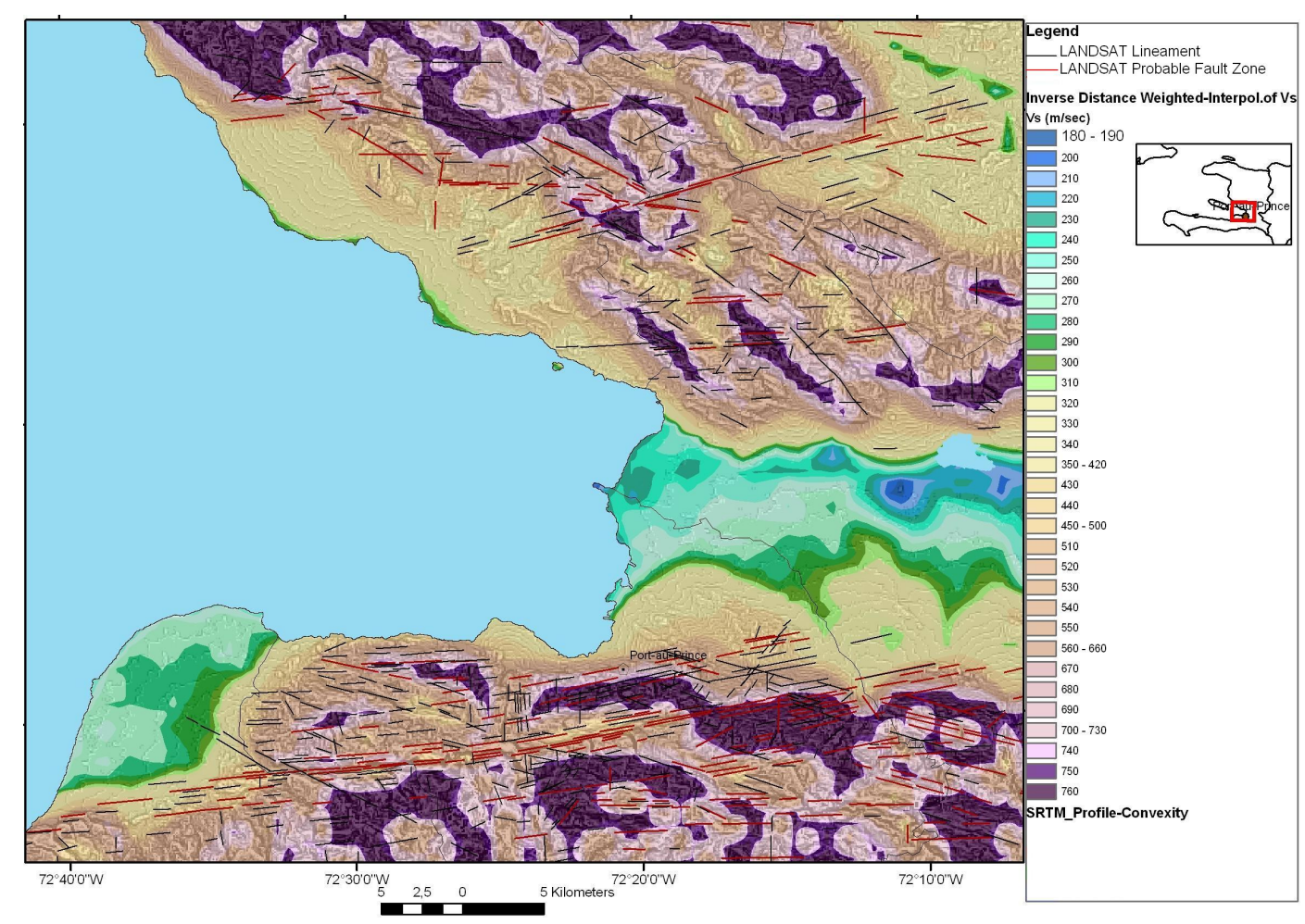

Fig. 14. Shear wave velocities $\left(V_{\mathrm{S}}\right)$ in the SW-Haiti area as derived by Wald and Allen (2007).

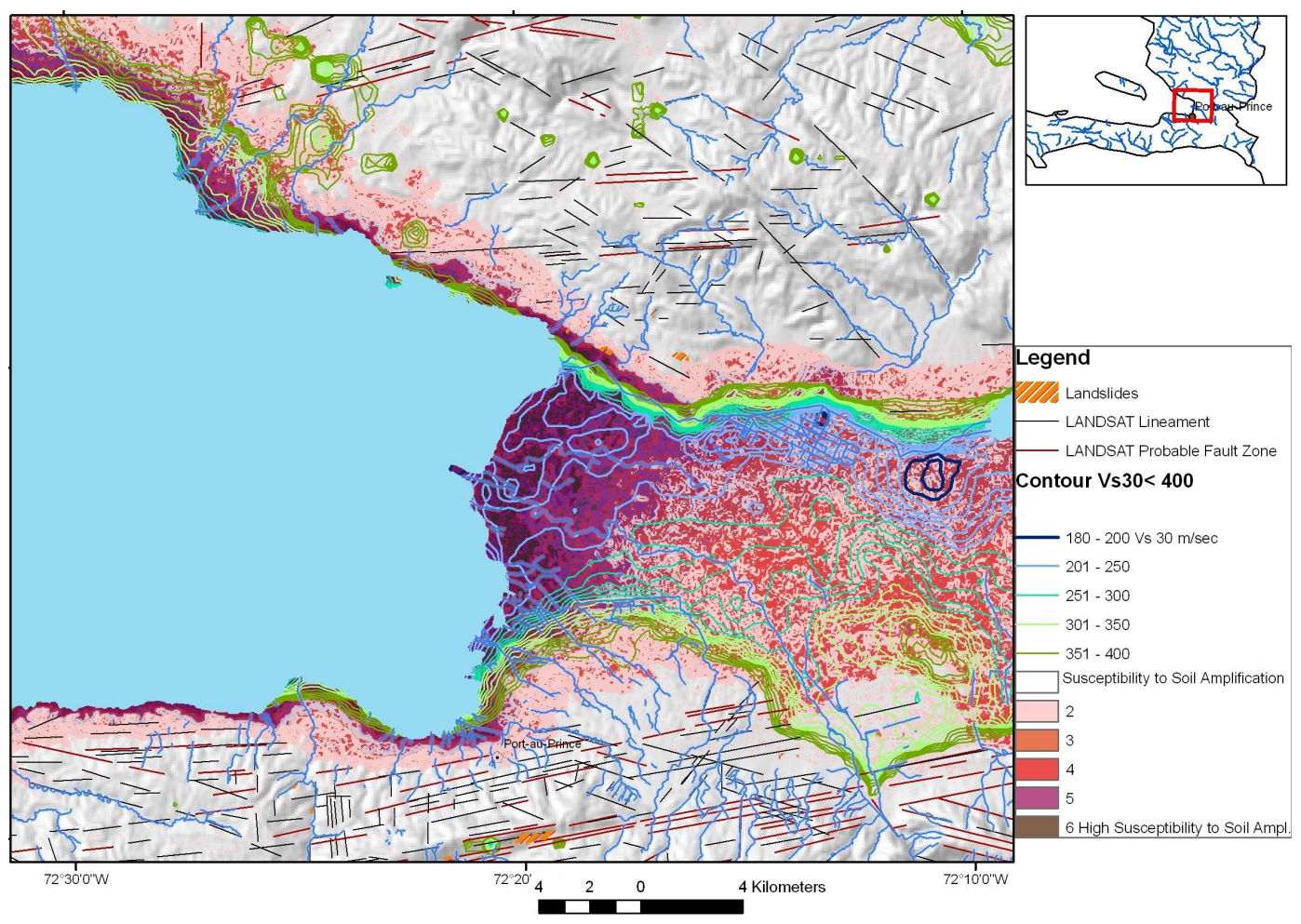

Fig. 15. Merging assumed shear velocity data $(\mathrm{Vs} 30<400 \mathrm{~m} / \mathrm{s})$ from USGS as contour lines with the soil amplification susceptibility map according to the weighted overlay-approach. 
with shallow shear-velocity observations, it is possible to recover, to first order, many of the spatially varying features of site-condition maps. It is worth to note that the resolution (30 arc sec) of the topography allows relatively detailed maps of site conditions. Many of these details come from smallscale topographic features that are likely to be manifestations of real site differences, such as basin edges and hills protruding into basins and valleys, and are thus easily visible due to their significant slope change signatures. Typically, these edges are important for predicting ground motion variations due to earthquakes (Wald and Allen, 2007). Thus, the from the SW-Haiti area derived $V_{\mathrm{S}}(\mathrm{m} / \mathrm{s})$ data were downloaded from the USGS and integrated and interpolated in ArcGIS for getting an overview of the estimated shear velocities in case of larger earthquakes (Figs. 14 and 15).

Lower shear wave velocities up to $400 \mathrm{~m} / \mathrm{s}$ as derived by Wald and Allen correspond quite well with the outcrop of unconsolidated, Quaternary sediments in the broader valley of Port-au-Prince. Merging the Weighted-OverlaySusceptibility map with the Vs-data derived by Wald and Allen (2007) there is a coincidence of areas assumed to be more susceptible to soil amplification according to the weighted overlay approach with areas of estimated lower shear wave velocities $\left(V_{\mathrm{S}}<250\right.$, Fig. 15$)$. When evaluating the building damage assessment maps of UNOSAT and DLR/ZKI, 2010, and Google Earth data) the highest amount of destroyed buildings after the January-2010-earthquakes was found in the dark-red areas of the soil-amplificationsusceptibility map (=assumed highest susceptibility to soil amplification due to the accumulation of factors influencing ground motion, Fig. 7), in the areas with estimated shear wave velocities Vs $30<250 \mathrm{~m} / \mathrm{s}$ and in areas underlaid by several, active fault zones intersecting each other.

\section{Conclusions}

The nearly world-wide available SRTM and ASTER-DEM data and LANDSAT imageries support a standardized, lowcost to no cost approach for the detection of some of the surface-near, causal factors of local site conditions influencing earthquake shock and damage intensity as well as of factors influencing earthquake related secondary effects. Aggregating factors influencing the surface-near earthquake ground motion in a GIS environment allows a first overview of areas with probably higher susceptibility to soil amplification, slope failure and flooding in SW-Haiti. A standardized procedure for mapping and assessing earthquake damage susceptibility has been developed based on the weighted overlay-approach which can serve to improve the efficiency of disaster monitoring, management and preparedness in Haiti. This approach integrates many types of data and geoprocessing tools that can automate the processes in an efficient manner. The advantage of GIS is that the system is open and additional data can be integrated as layers as soon as additional data are available. Thus, remote sensing data and GIS integrated evaluations and analysis can contribute to a better planning of cost and time-intensive geotechnical measurements that are important to consider when rebuilding the city of Port-au-Prince. The derived results from the whole process provide essential information for immediate response when future disasters will occur.

Acknowledgements. The author thanks the editor and reviewers. This article is dedicated to my nice Alina Cathrin Scheggia (†16 January 2010) inspiring me to this work with her ideas and idealism.

The support of EU, FP 7, Large Collaborative Research Project, IRIS - Integrated European Industrial Risk Reduction System, CP-IP 213968-2, is kindly acknowledged.

Edited by: K.-t. Chang

Reviewed by: L. Saro and P. F. Biagi

\section{References}

Allen, T. and Wald, D.: On the Use of High-Resolution Topographic Data as Proxy for Seismic Site Conditions $\left(V_{S 30}\right)$, B. Seismol. Soc. Am., 99(2A), 935-943, doi:10.1785/0120080255, April 2009.

Calais, E., Mazabraud, Y., de Le'pinay, M. B., Paul Mann, P., Mattioli, G., and Jansma, P.: Strain partitioning and fault slip rates in the northeastern Caribbean from GPS measurements, Geophys. Res. Lett., 29(18), 1856, doi:10.1029/2002GL015397, 2002.

Dolan, J. and Wald, D.: The 1943-1953 northcentral Caribbean earthquakes: Active tectonic setting, seismic hazards, and implications for Caribbean-North America plate motions, in: Active Strike-slip and Collisional Tectonics of the Northern Caribbean Plate Boundary Zone, edited by: Dolan, J. and Mann, P., Geol. S. Am. S., Boulder, 326, 143-169, 1998.

Ehret, D. and Hannich, D.: Seismic Microzonation based on Geotechnical Parameters - Estimation of Site Effects in Bucharest (Romania), EOS T. Am. Geophys. Un., San Francisco, 85(47), Fall Meet. Suppl., Abstract S43A-0972, Available at: http://adsabs.harvard.edu/abs/2004AGUFM.S43A0972E (last access: 28 May 2010), 2004.

Ehret, D., Kienzle, A., Hannich, D., and Wirth, W.: Seismic Microzonation based on geotechnical Parameters - Estimation of Site Effects in Bucharest (Romania), Geoph. Res. Abstr., 6, EGU04A-03708, 2004

Hannich, D., Hötzl, H., and Cudmani, R.: Einfluss des Grundwassers auf die Schadenswirkung von Erdbeben - ein Überblick, Grundwasser, 11(4), 286-294, 2006 (in German).

Giardini, D., Wiemer, S., Fäh, D., and Deichmann, N.: Seismic Hazard Assessment of Switzerland, Swiss Seismological Service, ETH Zürich, Zürich, Switzerland, 2004.

Gupta, R. P.: Remote Sensing in Geology, Springer-Verlag, BerlinHeidelberg-New York, 2003.

Lovett, R. A.: Haiti earthquake produced deadly tsunami - waves up to three metres high hit sections of the nation's coastline, Nature News, doi:10.1038/news.2010.93, published online, available at: http://www.nature.com/news/2010/100225/ 
full/news.2010.93.html (last access: 28 May 2010), 25 February 2010.

Manaker, D. M., Calais, E., Freed, A. M., Ali, S. T., Przybylski, P., Mattioli, G., Jansma, P., Prepetit, C., and de Chabalier, J. B.: Interseismic Plate coupling and strain partitioning in the Northeastern Caribbean, Geophys. J. Int., 174, 889-903, doi: 10.1111/j.1365-246X.2008.03819.x, available at: http://web.ics.purdue.edu/ ecalais/haiti/documents/ manaker_gji_2008.pdf (last access: 28 May 2010), 2008.

Mann, P., Prentice, C. S., Burr, G., Peña, L. R., and Taylor, F. W.: Tectonic geomorphology and paleoseismology of the Septentrional fault system, Dominican Republic, Geol. S. Am. S., 326, 63-123, doi:10.1130/0-8137-2326-4.63, available at: http://www.jsg.utexas.edu/news/pdfs/011310/Mann SFZ_1998.pdf (last access: 28 May 2010), 1998.

Schneider, G.: Erdbeben - Eine Einführung für Geowissenschaftler und Bauingenieure, Spektrum Akademischer Verlag, München, 2004 (in German).

Steinwachs, M.: Das Erdbeben am 19. September 1985 in Mexiko Ingenieurseismologische Aspekte eines multiplen Subduktionsbebens, in: Ausbreitungen von Erschtterungen im Boden und Bauwerk, 3. Jahrestagung DGEB, edited by: Steinwachs, M., TransTech.Publications, Clausthal, 1988 (in German).

Theilen-Willige, B. and Wenzel, H.: Local Site Conditions influencing Earthquake Shaking Intensities and Earthquake related Secondary Effects - A Standardized Approach for the Detection of Potentially Affected Areas using Remote Sensing and GIS-Methods - 10. Forum Katastrophenvorsorge, Katastrophen - Datenhintergrund und Informationen UN Campus, Bonn, available at: http://188.111.81.194/download/forum/ 10/Theilen-Willige_Wenzel_ExtAbst.pdf, http://188.111.81.194/ download/forum/10/Theilen-Willige_Wenzel_Praes.pdf (last access: 28.05.2010), 23-24 November 2009.

Theilen-Willige, B., Mulyasari Sule, F., and Wenzel, H.: Environmental Factors derived from Satellite Data of Java, Indonesia, in: Encyclopedia of Structural Health Monitoring, edited by: Boller, C., Chang, F.-K., and Fujino, J., John Wiley and Sons, Ltd., Chichester, UK, 2343-2354, 2008.

Tuttle, M. P., Prentice, C. S., Dyer-Williams, K., Pefla, L. R., and Burr, G.: Late Holocene Liquefaction Features in the Dominican Republic: A Powerful Tool for Earthquake Hazard Assessment in the Northeastern Caribbean, B. Seismol. Soc. Am., 93(I), 27-46, available at: http://www.jsg.utexas.edu/news/ pdfs/011310/Tuttle_et_al_2003_DR.pdf (last access:28.05.2010), February 2003.

Wald, D. J. and Allen, T. I.: Topographic Slope as a Proxy for Seismic Site Conditions and Amplification, B. Seismol. Soc. Am., 97(5), 1379-1395, doi:10.1785/0120060267, available at: http://www.bssaonline.org/cgi/content/abstract/97/5/1379 (last access: 28 May 2010), October 2007.

\section{Internet sources}

UNOSAT:

http://www.disasterscharter.org/image/journal/article.jpg? img_id=63885\&t=1263988941535

DLR, ZKI:

http://www.zki.dlr.de/applications/2010/haiti/182_de.htm, http://www.zki.dlr.de/applications/2008/haiti/158_en.html

NASA:

http://earthobservatory.nasa.gov/NaturalHazards/view.php?id= 42298

USGS, Seismic Hazard Program, Global Vs30 Map Server: http://earthquake.usgs.gov/hazards/apps/vs30/

Southern California Earthquake Center: http://www.scec.org/phase3/overview.html

\section{Earthquake and tsunami data free of charge}

Bundesanstalt für Geowissenschaften und Rohstoffe (BGR), Hannover:

http://www.bgr.bund.de/cln_145/nn_333452/DE/

Themen/Seismologie/Seismologie/Erdbebenauswertung/

Erdbebenkataloge/Kataloge__Bulletins/kataloge__bulletins__node.html?__nnn=true

Landeamt für Geologie, Rohstoffe und Bergbau (LGRB), Freiburg: http://www.lgrb.uni-freiburg.de/lgrb/Fachbereiche/ erdbebendienst

SED - Swiss Seismological Service International Seismological Centre: http://www.isc.ac.uk/search/custom/index.html

Stress Data of the World Stress Map (WSM) provided by GFZ Potsdam:

http://dc-app3-14.gfz-potsdam.de/pub/stress_data/ stress_data_frame.html

National Oceanic and Atmospheric Administration (NOAA) Satellite and Information Service: http://map.ngdc.noaa.gov/website/seg/hazards/viewer.html

GeoForschungsZentrum (GFZ) Potsdam, GEOFON programme and network:

http://geofon.gfz-potsdam.de/geofon/

\section{Satellite data free of charge}

Global Land Cover Facility: http://glcfapp.glcf.umd.edu:8080/esdi/index.jsp

NASA:

https://zulu.ssc.nasa.gov/mrsid/mrsid.pl

USGS:

http://edcsns17.cr.usgs.gov/NewEarthExplorer/

\section{Digital elevation data free of charge}

http://srtm.csi.cgiar.org/SELECTION/inputCoord.asp http://glcfapp.glcf.umd.edu:8080/esdi/index.jsp http://www.gdem.aster.ersdac.or.jp/search.jsp 